\title{
Responding to inflight medical emergencies can be stressful for doctors
}

\author{
n Cite as: CMAJ 2018 March 19;190:E339-40. doi: 10.1503/cmaj.109-5569
}

Posted on cmajnews.com on Feb. $26,2018$.

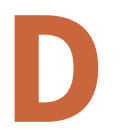
r. Sarah Giles had just put her headphones on, and was settling in for a flight to London, England, when she heard an announcement requesting a doctor. She turned and saw a man face down in the aisle. "I just went," recalled the emergency doctor and fellow at the Munk School of Global Affairs. As Giles administered oxygen, an airline flight attendant asked if the plane, now over Newfoundland, should be landed.

"I was like, 'Can I get a set of vitals, first? Can you give me five minutes?'" Giles recalled.

It didn't take long for Giles to realize the man had simply fainted. He'd taken his bloodpressure pills earlier than normal, and didn't eat or drink before the flight to avoid using the plane's toilets.

Many doctors, like Giles, don't think twice about helping during inflight health emergencies. But the experience can be stressful. Physicians have to work in cramped quarters, surrounded by curious onlookers. They may also face the tough decision of recommending whether to divert the plane expensive for the airline, distressing for passengers.

Doctors aren't required by law to volunteer to help airplane passengers, although many view it as an ethical duty. "We're lucky to have the skills and the training we do, so we should use those skills to help people," said Dr. Joshua Tepper, a family physician and CEO of Health Quality Ontario.
Doctors have little to worry about from a legal standpoint. Good Samaritan laws allow physicians to help someone in distress, said Dr. Alun Ackery, an emergency physician at St. Michael's Hospital. And the Canadian Medical Protective Association will cover physicians who provide passengers and to help secure the space. Passengers can be asked to move to other available seats or into the hallway, and the galley of an airplane can be a good space to assess a mobile patient. Individuals travelling with the patient should remain close by, as they can provide useful clinical information.

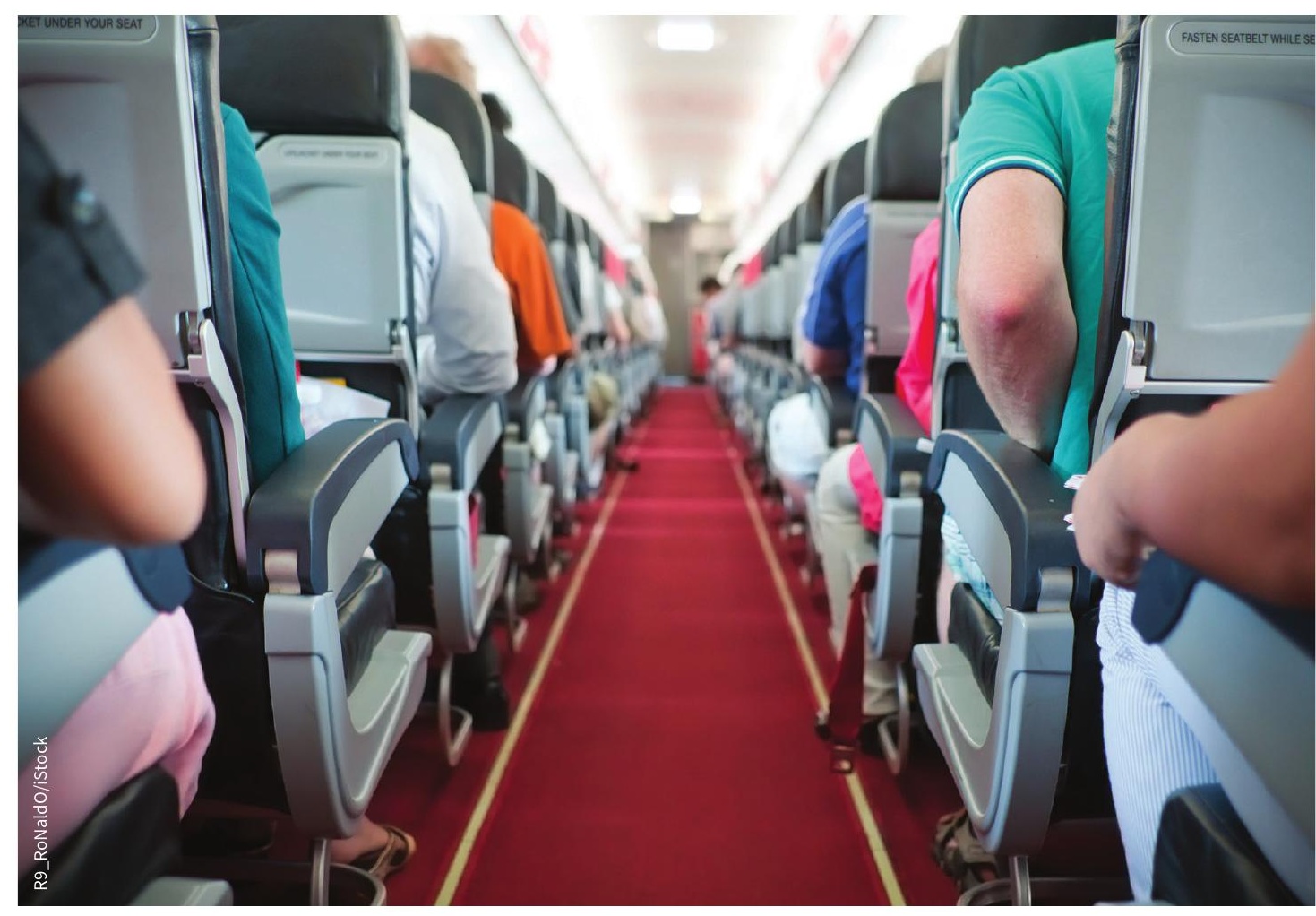

The cramped quarters of an airplane can be a stressful environment for a doctor onboard who responds to a medical emergency. care on airplanes, including formerly represented doctors who have retired. No Canadian doctor has faced a lawsuit for care provided on a plane.

In a CMAJ Analysis article, Ackery recommended creating space and turning on cabin lights to assess the patient. Attendants should be recruited to help manage nearby
Ackery also points out that the stethoscope is often of limited use because of the loud airplane noise, and it's important to keep in mind that, at most cruising altitudes, normal oxygen saturation is approximately $90 \%$ of what it is on the ground.

All airlines have a ground-based physician on call, and a passenger who 
happens to be a doctor, regardless of specialty, can be a helpful go-between, said Dr. Anna Carvalho, an emergency physician in Montreal and director of a continuing medical education course for onboard medical emergencies. "Just being able to take a pulse or eyeball 'sick versus not sick' is of great assistance to the ground-based physician," she said.

Many of the medical issues that arise on airplane are related to altitude or the stress of flying. "There are a lot of nervous flyers out there who just need some assurance," said Dr. Alan Ruddiman, who served as president of Doctors of BC last year.

The lowered oxygenation can also cause health problems. If someone already has low oxygen levels due to pneumonia, for example, flying at high altitude could bring about shortness of breath, chest pain and altered consciousness. Even someone with heart disease who has good oxygen saturation on the ground could have problems in the air. And the longer the flight, the more likely issues will arise.

Fortunately, there is often a doctor on an airplane. Ruddiman recalls flying home with colleagues from a conference when the call was put out for a doctor, and 30 people stuck up their hands. If there are multiple physicians onboard, there's usually a short conversation to figure out which doctor is best suited to manage the patient. According to Ackery, a nurse or paramedic may be better suited for the task in some cases.

"I've been struck with how incredibly collegial it is, and how everybody is willing to come together as an impromptu team," said Tepper.
Of course, there's always paperwork, even after unexpected medical emergencies on airplanes. Tepper likes to record the encounter in his own documents as well. "I lock it up securely when I'm home, just in case I need my own record."

As a reward to her assistance in the air, Giles has received a bottle of wine and airplane points. Tepper once received a letter of thanks from an airline. According to Ruddiman, however, North American airlines could do a better job of acknowledging the volunteer efforts of doctors. "There's a lot of anxiety. It's an artificial environment, and you're very aware that things could go wrong in a hurry," he said. "A formal thank-you would go a long way."

Wendy Glauser, Toronto, Ont. 